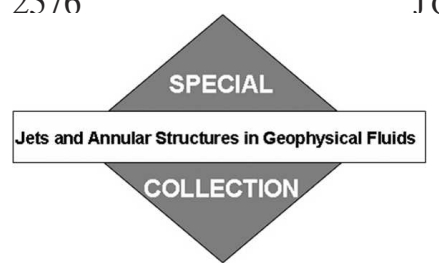

\title{
Breaking Waves at the Tropopause in the Wintertime Northern Hemisphere: Climatological Analyses of the Orientation and the Theoretical LC1/2 Classification
}

\author{
O. Martius, C. Schwierz, And H. C. Davies \\ Institute for Atmospheric and Climate Science, ETH Zürich, Zürich, Switzerland
}

(Manuscript received 15 May 2006, in final form 27 September 2006)

\begin{abstract}
Breaking waves on the tropopause are viewed as potential vorticity (PV) streamers on middle-world isentropic levels. A Northern Hemisphere winter climatology of the streamers' spatial distribution and meridional orientation is derived from the 40-yr ECMWF Re-Analysis (ERA-40) dataset, and used to assess the nature and frequency of occurrence of breaking synoptic-scale waves. The streamers are grouped into two classes related to the so-called cyclonic (LC2) and anticyclonic (LC1) patterns, and the ambient wind strength and wind shear is also noted.

It is shown that the occurrence of cyclonic and anticyclonic PV streamers exhibits a distinct spatial variability in the horizontal and the vertical. The majority of cyclonic PV streamers are found on lower isentropic levels that intersect the tropopause at more poleward latitudes, whereas anticyclonic streamers predominate at higher elevations in the subtropics.

An analysis of the streamer patterns for the two phases of the North Atlantic Oscillation (NAO) reveals significant differences in the location and frequency of both cyclonic and anticyclonic streamers in the Euro-Atlantic region on the $310-\mathrm{K}$ isentropic level. Likewise, for the two phases of the ENSO and the Pacific-North American (PNA) pattern, there are marked differences in the frequency pattern of cyclonic streamers. An examination of the tropopause-level hemispheric flow pattern at the time of and prior to a streamer's formation indicates a linkage to the presence or absence of double jet structures.
\end{abstract}

\section{Introduction}

Meridional and vertical undulations of synoptic scale associated with quasi-horizontal wave propagation are characteristic features of the short-term variability of the dynamical tropopause. If the horizontal amplification of these undulations attains an irreversible character, the process is referred to as wave breaking (McIntyre and Palmer 1983). During such breaking events, the strongly deformed intrusions of stratospheric air into the troposphere only retain a thin connection to the stratospheric body of air. These structures are socalled stratospheric potential vorticity (PV) streamers (Appenzeller and Davies 1992). Stratospheric PV streamers are associated with a number of atmospheric flow phenomena. They can be viewed as positive upper-level PV anomalies that are closely linked to surface weather patterns (Hoskins et al. 1985). They have

Corresponding author address: Olivia Martius, Institute for Atmospheric and Climate Science, ETH Zürich, 8092, Switzerland. E-mail: olivia@env.ethz.ch been linked to events of heavy Alpine precipitation (e.g., Massacand et al. 1998; Martius et al. 2006) and, because of their irreversible nature, they are areas of enhanced exchange processes between the stratosphere and the troposphere (e.g., Sprenger et al. 2007).

This paper presents an observation-based climatological analysis of the form of such PV streamers. The shape of PV streamers is highly variable and can have an important influence on all of the above-mentioned processes. This study sets out a novel method to categorize the PV streamer orientation by adopting the concept of the archetypal cyclonic and anticyclonic baroclinic wave life cycles that stem from idealized simulations of the evolution of baroclinic waves (e.g., Davies et al. 1991; Thorncroft et al. 1993).

\section{a. Baroclinic life cycles and background flow setting}

The life cycles of baroclinic waves are a long-standing theme in meteorological research [see Simmons (1998) for a review]. The life cycle concept is of direct interest to the forecasting community (Bjerknes and Solberg

DOI: $10.1175 / J A S 3977.1$ 
1922) and also plays a central role in the understanding of low-frequency phenomena such as atmospheric blocks (e.g., De Pondeca et al. 1998) and the North Atlantic Oscillation (Benedict et al. 2004).

Important milestones in the history of the concept were the experiments by Simmons and Hoskins (1978, 1980), who applied different settings of barotropic meridional shear in idealized experiments. They identified a cyclonic life cycle that develops in model runs where a cyclonic horizontal shear anomaly is superimposed on a zonally symmetric basic state. Davies et al. (1991) extended these experiments, using a larger variety of different shear conditions. Three different classes of the tropospheric and surface synoptic development are found for flow settings with no, cyclonic, or anticyclonic shear added to the basic state. Thorncroft et al. (1993, hereafter THM) repeated the idealized experiments of Simmons and Hoskins using a model of higher resolution. They give a detailed description of two life cycles, termed LC1 (anticyclonic) and LC2 (cyclonic).

In the final stage of the anticyclonic life cycle (LC1), the form of the upper-level wave changes as it becomes exposed to the anticyclonic shear on the southern edge of the jet. It elongates in the northeast-southwest (NESW) direction and narrows in its zonal extent (THM), and thereafter it often breaks up into upper-level cutoff vortices (THM; Appenzeller et al. 1996).

During the cyclonic life cycle (LC2), the disturbance remains on the cyclonically sheared side of the jet and wraps up cyclonically. The breaking wave remains relatively broad and no cutoffs form (THM). The life cycles differ significantly not only in terms of their upper-level development, but also in the synoptic evolution of the associated surface cyclones, anticyclones, and fronts (e.g., Davies et al. 1991; Wernli et al. 1998).

One focus of this paper is the description of the largescale flow (and more particularly the jets) at the time of and prior to the PV streamer events. Shapiro et al. (1998) emphasize that the location of the baroclinic wave relative to the multiple jets (subtropical, polar, arctic) has a crucial influence on the life cycles that the waves undergo (see their Fig. 4). Peters and Waugh (2003) discuss the type of breaking waves expected for four single and double jet basic states from a shear and PV advection standpoint. However, the understanding of the various interactions among multiple jets and their influence on the life cycles of baroclinic waves is still incomplete. For example, cyclonic life cycles are observed for both double jet (Shapiro et al. 1998) and single jet (Lee and Kim 2003) settings. Akahori and Yoden (1997) find in their idealized simulations that the meridional position of the jet crucially influences the life cycle that a wave undergoes. Narrow and strong jets support cyclonic wave breaking whereas locally broad and weak jets are a favorable flow setting for anticyclonic wave breaking (Esler and Haynes 1999). Both these studies confirm the observational evidence of Hartmann (1995) for the Southern Hemisphere. Hartmann identified primarily anticyclonic life cycles in the case of a northward-shifted extratropical jet in the presence of a subtropical jet; whereas in the case of southward-shifted, narrow midlatitude jet, a preference was noted for cyclonic wave breaking on the extratropical jet.

Several key issues of our subsequent analyses relate to the foregoing remarks. First, the form and orientation of potential vorticity streamers contains information about the mature, nonlinear stage of baroclinic life cycles. It is therefore appropriate that the climatology of PV streamers be grouped into two classes, a cyclonic (LC2) and an anticyclonic (LC1) class according to the main orientation of the streamers. The motivation for this lies in the findings of the studies cited above that have identified the orientation of the breaking wave as a major characteristic of different types of baroclinic wave life cycles.

Second, in the case of an idealized zonally symmetric single jet setting, the cyclone life cycles are determined primarily by the asymmetry of the meridional shear and are in addition sensitive to the wavenumber of the disturbances as well as to the model geometry and influences of the ageostrophic circulation (THM; Balasubramanian and Garner 1997; Hartmann and Zuercher 1998). Adopting a vortex- rather than a jet-centered viewpoint, anticyclonic life cycles are observed to occur when strong anticyclonic vortices deform a cyclonic vortex and vice versa for the cyclonic life cycles (Orlanski 2003). Because of asymmetries in the growth of vortices, stronger low-level forcing will lead to cyclonic life cycles and weaker forcing to anticyclonic life cycles (Orlanski 2003).

Third, previous studies that have identified the flow settings favoring the various life cycles have, on the one hand, highlighted the seminal influence of the relative meridional location of the jets; and, on the other hand, have hinted that for "real-world" settings, the situation is considerably complicated by interactions between multiple jets. Indeed results on the relationship between single and multiple jet environments and different classes of breaking waves are not clear-cut.

\section{b. Link to the global teleconnection patterns}

Some previous studies have examined the feedback processes between major Northern Hemisphere teleconnection patterns and breaking synoptic-scale waves. 
The background flow predominantly determines the life cycles of baroclinic waves, rather than the form or the strength of the initial disturbance (THM; Harnik and Chang 2004). The low-frequency variability of the background flow on the other hand can be substantially influenced by the waves (e.g., Whitaker and Sardeshmukh 1998; Swanson 2002).

The characteristics of the mean flow during opposite extreme phases of three tropical and northern hemispheric teleconnection patterns and the interaction with breaking waves are discussed here. The extratropical circulation over the Pacific varies significantly during opposite El Niño-Southern Oscillation (ENSO) phases (Bjerknes 1969). The subtropical jet is stronger and shifted southward over the western Pacific during the warm phase, while the ridge over the eastern part of the Pacific is more pronounced during the cold phase (Trenberth et al. 1998). Concomitantly, an upstream (downstream) shift $\left(\sim 20^{\circ}\right)$ of the maximum eddy activity is observed over the central Pacific during La Niña (El Niño) (e.g., Chen and Van den Dool 1997; Swanson 2000). These changes of the mean flow have the potential to influence the life cycles of cyclones in the vicinity. An observational PV-based analysis of different life cycles in the eastern Pacific during the strong El Niño of 1997/98 and the La Niña episode of 1999 shows a prevalence for cyclonic wave-breaking events during the warm phase and the reverse for the cold phase (Shapiro et al. 2001). These findings are confirmed by a numerical experiment of Orlanski (2003).

Since the effects of the Pacific-North American (PNA) pattern on the eastern Pacific flow conditions are comparable to those during ENSO (Horel and Wallace 1981), a similar variability of the cyclone life cycles can be expected for the opposite PNA flow states.

Franzke et al. (2004) and Benedict et al. (2004) propose a close link between the life cycle of extratropical cyclones and the North Atlantic Oscillation. Looking at a large number of cases, they find that both phases of the NAO can be dynamically understood as breaking synoptic-scale waves. The negative NAO phase arises in situ through cyclonic wave breaking on the extratropical jet over the western Atlantic. The positive NAO phase originates upstream from two separate anticyclonically breaking waves on the subtropical jet.

\section{c. Outline}

The main objectives of this paper are to

1) present and discuss the climatological spatial distribution of PV streamers with a cyclonic or an anticyclonic orientation on the tropopause of the Northern Hemisphere;
2) describe and quantify the variations in the frequency of PV streamers with a cyclonic or an anticyclonic orientation during opposite phases of three major Northern Hemisphere and tropical teleconnection patterns over a 44 -yr time span; and

3) discuss the climatological flow, with a special focus on the jet streams, on the tropopause at the time of and prior to the detection of different types of streamers.

The paper is organized as follows. Section 2 contains a brief description of the method used to assemble a climatology of PV streamers and to determine their orientation. Examples for cyclonic and anticyclonic life cycles are presented in section 3. The results of the climatological analysis are discussed in section 4. In section 5, the climatological ambient mean flow field is studied at the time of the detection of cyclonic and anticyclonic streamers. In the last section, the findings of the climatological analyses are discussed and summarized.

\section{Method}

This study makes use of a climatology of PV streamers. The climatology has been calculated by applying the streamer detection routine of Wernli and Sprenger (2007) to the 40-yr European Centre for MediumRange Weather Forecasts (ECMWF) Re-Analysis (ERA-40) dataset (1958-2002; Uppala et al. 2005). The ERA-40 fields are interpolated to a spatial resolution of $1^{\circ} \times 1^{\circ}$ and have a temporal resolution of $6 \mathrm{~h}$. The PV streamer routine objectively detects meridionally elongated PV structures with a narrow apex on tropopause crossing isentropic surfaces. In brief, the routine works as follows. First, the dynamical tropopause is determined on several $(310-350 \mathrm{~K}, \Delta 5 \mathrm{~K})$ isentropic levels by identifying the southernmost closed 2-PVU contour that encircles the pole. Then, points along this contour are identified, which are separated by a small direct great circle distance $(<800 \mathrm{~km})$ but with more than $1500 \mathrm{~km}$ of contour length between them. These points on the contour are called endpoints and the point located in the middle of the connection line between these two points is called root point. The area enclosed by the contour between the endpoints is identified as a streamer (Fig. 1) and stored as in binomial field, which is used to calculate streamer frequencies. It is to be noted that the routine as applied here only detects PV streamers and not PV cutoffs.

The choice to detect streamers on multiple isentropic levels transecting the dynamical tropopause and not on the dynamical tropopause itself is based on technical 


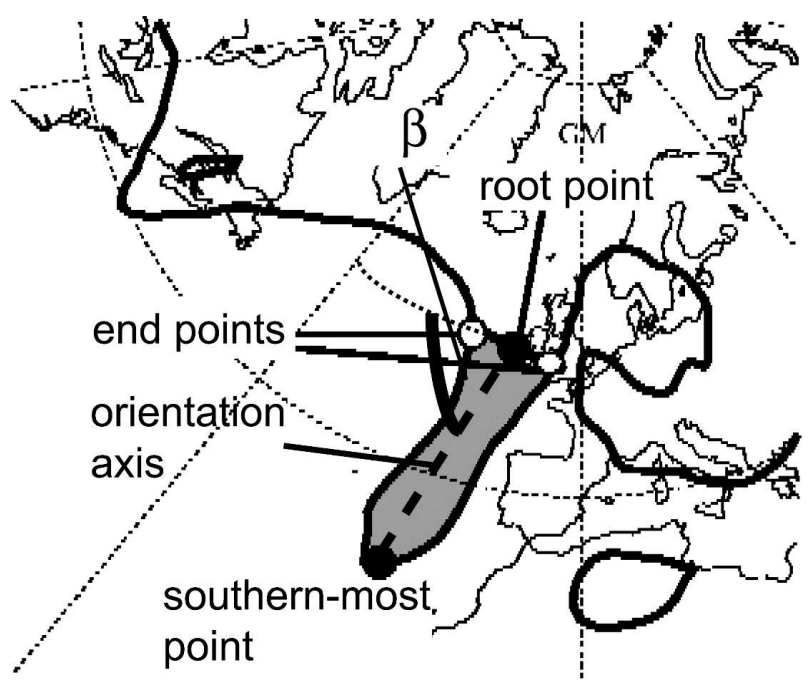

FIG. 1. Schematic depiction of the PV streamer detection algorithm and the determination of the PV streamer orientation angles. The streamer area is enclosed by the contour between the two endpoints of the streamer (gray shading). The streamer classification scheme uses the angle $(\beta)$ between the zonal direction and the orientation axes of the streamer indicated by the curved thick black line.

reasons [i.e., nonunique definition of the 2-PVU isosurface, where $1 \mathrm{PV}$ unit $(\mathrm{PVU})=1.0 \times 10^{-6} \mathrm{~m}^{2} \mathrm{~s}^{-1} \mathrm{~K}$ $\left.\mathrm{kg}^{-1}\right]$ and dynamically motivated reasons (i.e., $\mathrm{PV}$ dynamics on isentropic surfaces). An analysis on the dynamical tropopause on the other hand offers the advantage of a more integrative perspective when addressing the interaction of the streamers with multiple jets. An overview of the mean winter location of the isentropic surfaces between 300 and $340 \mathrm{~K}$ and the dynamical tropopause in the Atlantic and the Pacific basin is given in Fig. 2.

(a)

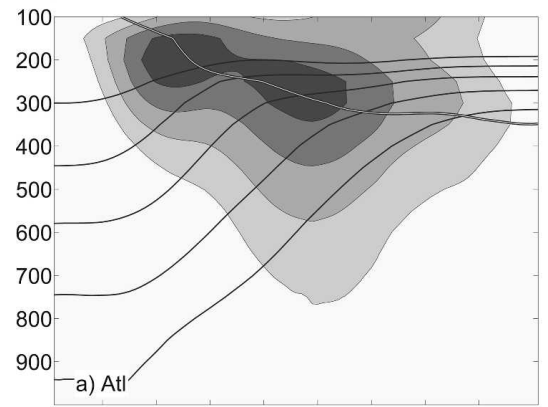

ON $10 \mathrm{~N} 20 \mathrm{~N} 30 \mathrm{~N} 40 \mathrm{~N} 50 \mathrm{~N} 60 \mathrm{~N} 70 \mathrm{~N} 80 \mathrm{~N} 90 \mathrm{~N}$
Streamers with preferential NW-SE (cyclonic) or NE-SW (anticyclonic) orientation are extracted from the PV streamer dataset in the following way. The orientation of the PV streamers is determined by calculating the angle $(\beta)$ between a zonal base line and the orientation axis of the streamer (cf. Fig. 1), a line connecting the root point of a streamer with its southernmost point. PV streamers with orientation angles smaller than $75^{\circ}$ are assigned to the anticyclonic group and PV streamers with orientation angles of $105^{\circ}$ and more are counted among the cyclonic group. The choice of these angles is to a certain degree arbitrary but sensitivity tests using different angles between $90^{\circ}$ and $75^{\circ}$, and $90^{\circ}$ and $105^{\circ}$ show no qualitative and relatively small quantitative differences in the results. The two streamer classes contain together about four-fifths of the total number of streamers. The PV streamers with an angle between $75^{\circ}$ and $105^{\circ}$ are assigned to a neutral group and are not investigated further in this paper.

Note that the streamer angles are defined relative to a zonally orientated base line and not relative to the orientation of the instantaneous local waveguide. This is mainly because of technical reasons; the local orientation of the instantaneous waveguide is difficult to determine objectively. Using the climatological mean orientation of the 2-PVU contour on each isentropic surface could possibly circumvent this technical problem. This climatological waveguide is not entirely zonally orientated; a trough is situated over eastern North America and a ridge over the eastern Atlantic. The inclination of the contour would lead to an overestimation of the anticyclonically (cyclonically) sheared streamers at the upstream (downstream) edge of the trough in our climatology. Moreover, it is evident that the meridional deformation of the climatological mean

\section{(b)}

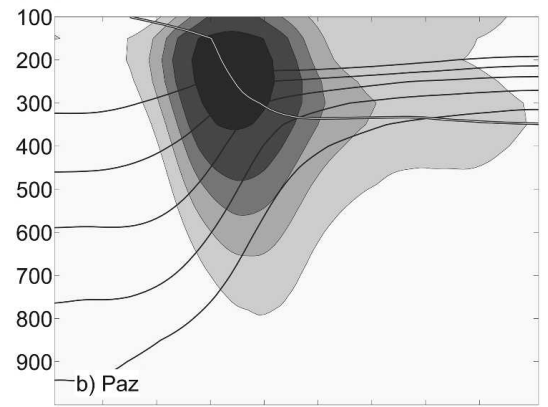

ON 10N 20N 30N 40N 50N 60N 70N 80N 90N

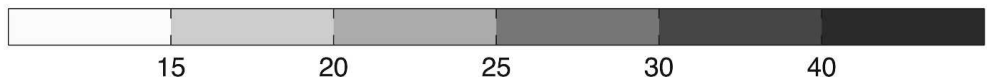

FIG. 2. Winter mean wind velocity (shaded), potential temperature $(300-340 \mathrm{~K}$, interval $=$ $10 \mathrm{~K}$, bold black lines) and the dynamical tropopause (2-PVU isosurface, black and white line) averaged (a) over the Atlantic basin $\left(60^{\circ} \mathrm{W}-20^{\circ} \mathrm{E}\right)$ and (b) the Pacific basin $\left(120^{\circ} \mathrm{E}-120^{\circ} \mathrm{W}\right)$. 
contour is strongest on the lowest isentropic level where it is collocated with the extratropical jet. In contrast, the mean contour becomes more zonally orientated on the higher levels where its course follows that of the subtropical jet. The maximum inclination of the climatological 2-PVU contour does not exceed $15^{\circ}$ on the 310-K level. Hence by choosing threshold angles of $75^{\circ}$ and $105^{\circ}$, hardly any $\mathrm{PV}$ streamers are counted among the "wrong" class. It is however important to point out that the climatological 2-PVU contour itself, being the composite of 2-PVU contour deformations caused by individual streamer events and waves, contains information regarding the preferential orientation of the streamers.

Some idealized studies (Davies et al. 1991; Shapiro et al. 1998) distinguish between three different life cycle types. These are a neutral (LC1) and an anticyclonic (LC3) life cycle that both exhibit a similar upper-level PV form evolution and a cyclonic life cycle (LC2). The classification used here allows no further distinction between LC1 and LC3 type streamers, both are counted among the anticyclonic group and called anticyclonic (LC1) henceforth.

The form of the PV streamers identified by the streamer detection routine can be highly variable. For some of these forms the calculation of the orientation angle as described above is ambiguous. Hence, the frequencies discussed later are associated with uncertainties and are not to be viewed in a sacrosanct manner. The horizontal shear used for various analyses is calculated perpendicular to the velocity field.

In the following discussion, only the winter months [December-February (DJF)] are analyzed. The standardized daily NAO/PNA indexes used in section 4c are taken from the Climate Prediction Center (CPC) and are based on the National Centers for Environmental Prediction (NCEP) reanalysis data. To compile the ENSO composites monthly Niño-3.4 $\left(5^{\circ} \mathrm{N}-5^{\circ} \mathrm{S}, 170^{\circ}-\right.$ $\left.120^{\circ} \mathrm{W}\right) \mathrm{SST}$ anomalies from the CPC are used. The daily and monthly data are grouped according to their teleconnection index into a positive sample (index $>1 \sigma$ ), a negative sample (index $<-1 \sigma$ ) and the rest.

\section{Illustrative examples}

Examples of a cyclonically breaking wave and streamer formation on a low isentropic surface $(310 \mathrm{~K})$ and an anticyclonically breaking wave and streamer formation on a higher, subtropical isentropic level (340 K) are presented in Figs. 3a,b. The development of the waves and streamers are discussed and their evolution interpreted using information on the ambient wind shear.

To give a compact overview of the prevailing flow across several isentropic surfaces, the wind velocity and associated meridional shear and the potential temperature $(\theta)$ isolines are shown on the dynamical tropopause (i.e., 2-PVU isosurface). Potential temperature isolines on the 850-hPa surface are also shown to indicate the location of the surface baroclinic zone, which is situated in areas of enhanced- $\theta$ gradients. The wave disturbances that break cyclonically are marked with an A (A1 in row 1 and 3 and A2 in row 2 and 4, note that A1 and A2 mark the position of the same feature in different fields) and the anticyclonically breaking waves accordingly with a B in both figures.

In the first panel of Fig. 3a (1800 UTC 12 February $1963)$ the 310- and 340-K isolines are coaligned and are in spatial proximity over the eastern United States, indicating a steep tropopause that is accompanied by a jet maximum in that area. Over the central Atlantic Ocean, the 310- and 340-K contours diverge and the jet is stronger along the extratropical contour $(310 \mathrm{~K})$ and remains so during the subsequent time steps. A1 marks the trough that will develop later in the evolution into a PV streamer.

During the following days (1200 UTC 13 February 1963-0000 UTC 15 February 1963), the jet over the continental United States strengthens significantly and extends eastward. This jet advects high- $\theta$ air northeastward, which is the counterpart of the northeastward advection of low-PV air on an isentropic surface (C, Fig. 3a, third row). This leads to an amplification of the anticyclonic circulation upstream of the developing anticyclonic streamer (B) in the central Atlantic and this circulation intensifies the stretching of the streamer farther in the NE-SW direction. At the same time, a strengthening of the subtropical jet is visible (D, Fig. 3a, third row) along the southern edge of the breaking wave (B). Throughout the whole episode, the anticyclonic steamer is located to the south of the surface baroclinic zone (dashed lines). The panels in row 2 and 4 show that the breaking of the anticyclonic wave occurs to the south and downstream of the strongest jet in an area of weak meridional shear. The subtropical streamer is detected by the routine at 0000 UTC on 15 February 1963 (Fig. 3a, last panel third and fourth row) and marked by B1.

In the same time period (13-15 February 1963; Fig. 3a), a cyclonic wave-breaking event takes place along the extratropical jet over the northern central Atlantic (A). The asymmetry of the extratropical jet and the shear associated with it are noteworthy. The velocity gradients along the extratropical jet's northern, cyclonic edge are steeper than those along the southern edge (e.g., 0000 UTC 13 February 1963). Consequently, the breaking wave rolls up cyclonically. During this de- 


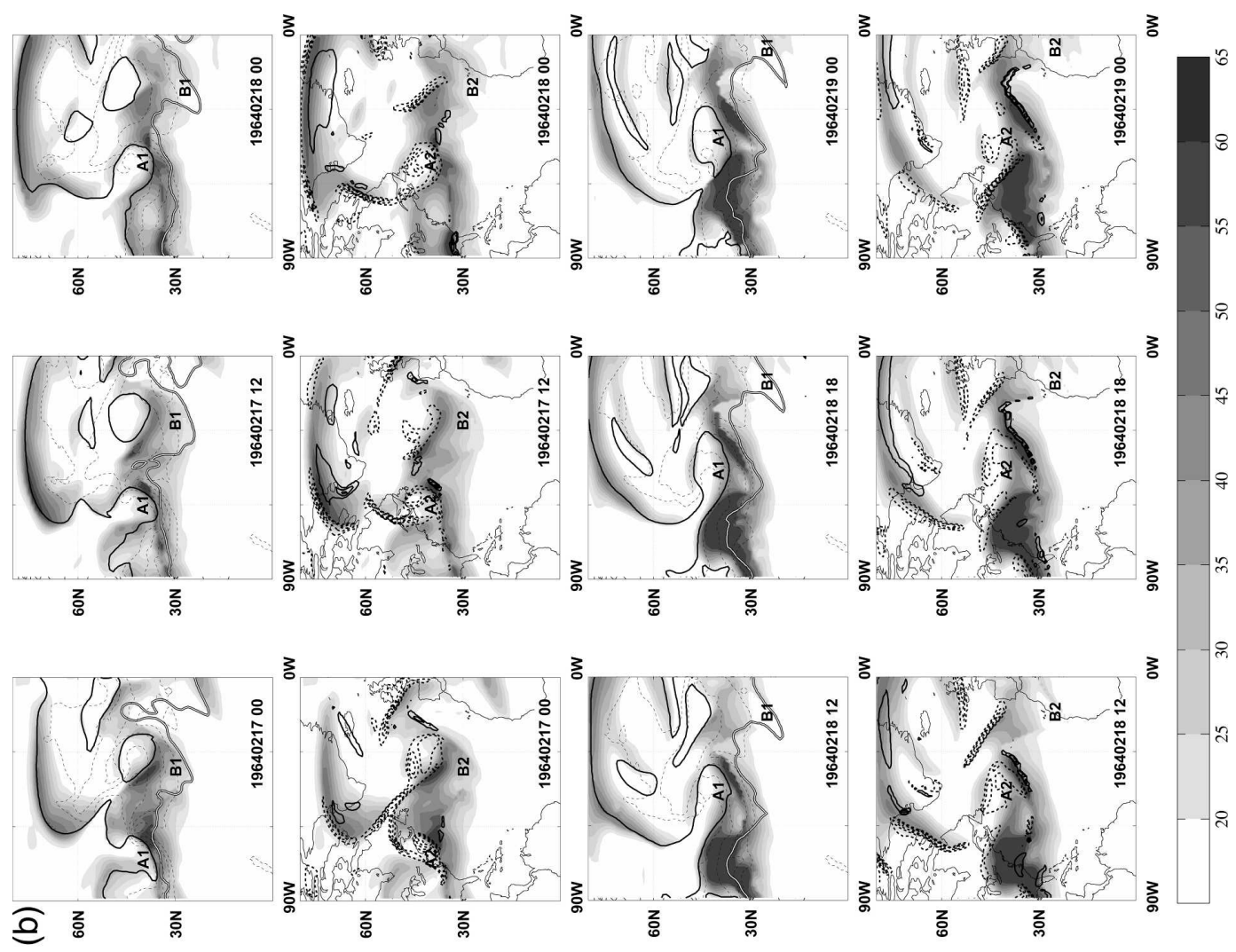

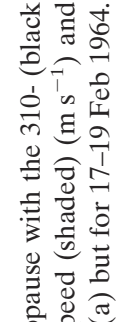

0
0
0
0
0
0
0
0

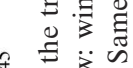

范兑全

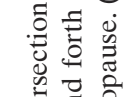

诺

要它

등 웜

कि

焉金的

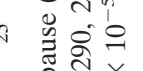

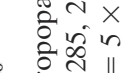

월

产

잉ㅇ
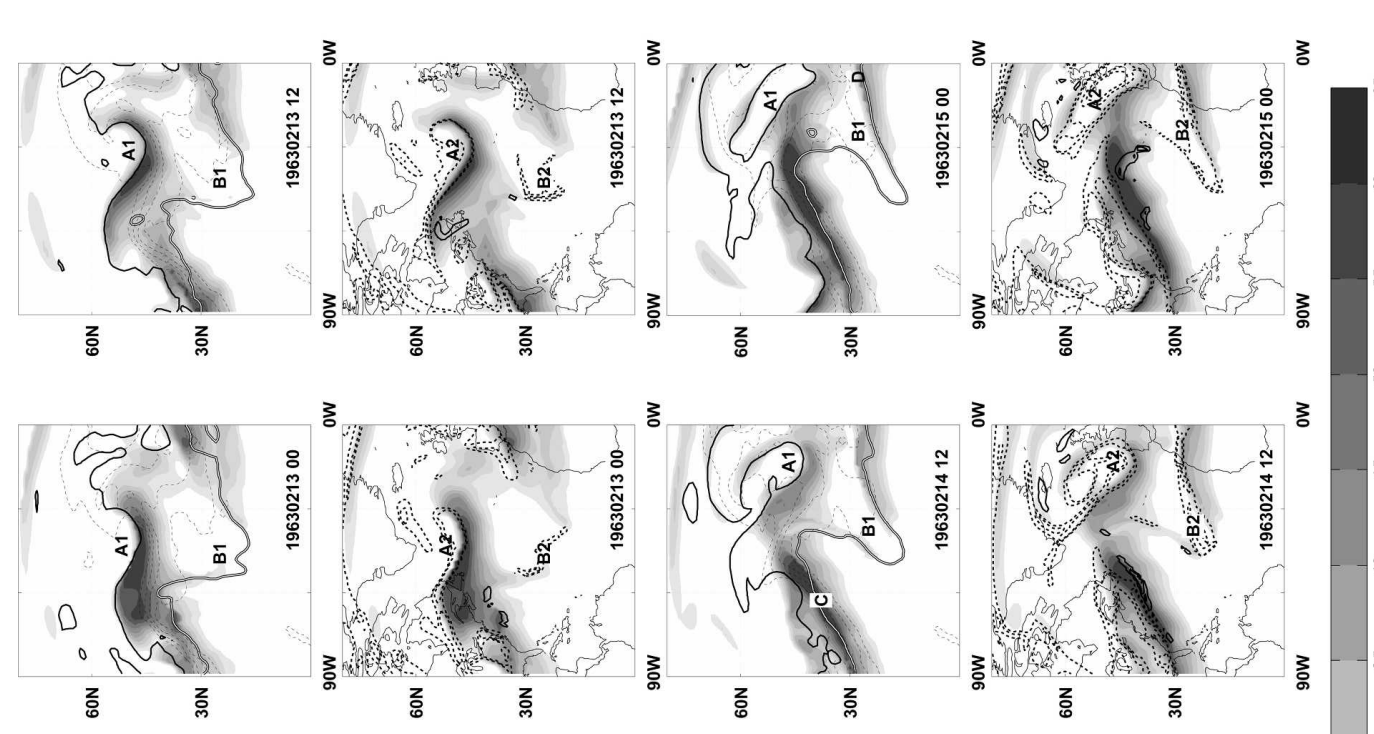

ธี

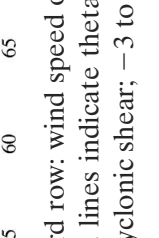

的氞券完

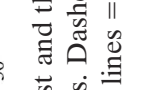

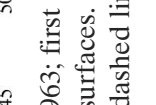

अ

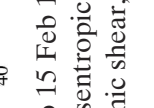

…ำ

๙

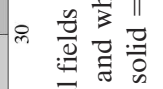

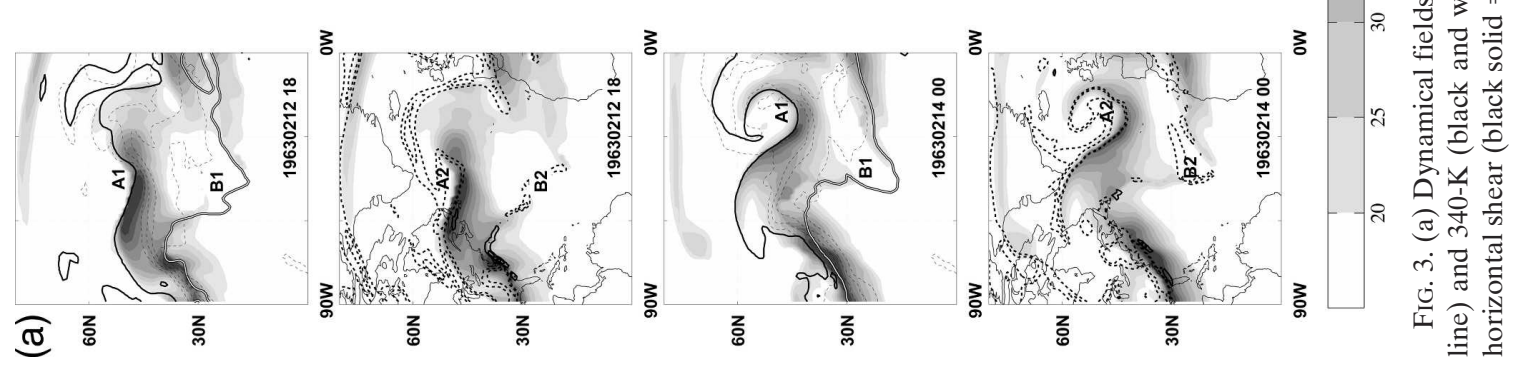



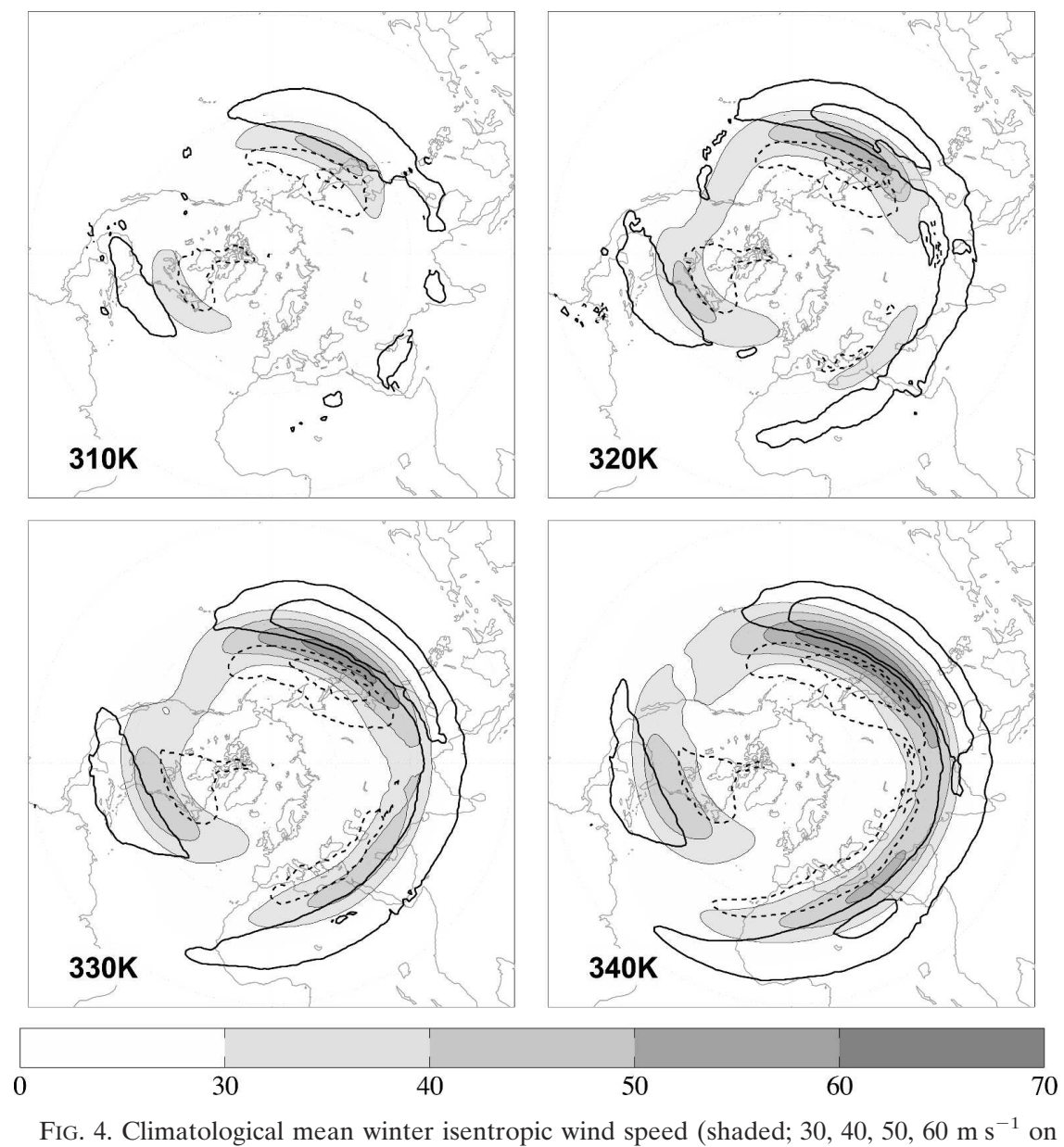
330 and $340 \mathrm{~K}$ ) and horizontal shear (solid lines = anticyclonic shear, dashed lines = cyclonic shear; values are $\left.1.5,3 \times 10^{-5} \mathrm{~s}^{-1}\right)$.

velopment, the upper-level feature is located slightly to the north of a strong surface baroclinic zone. The routine identifies the streamer at 0000 and 1200 UTC on 14 February 1963 (Fig. 3a, first and second panel, third and fourth row), the streamer is marked by A1.

A different mechanism supporting a cyclonic development is shown in Fig. 3b. A wave is present in the form of a strong meridional deformation of the $310-\mathrm{K}$ isoline (0000 UTC 17 February 1964, first panel). The breaking wave starts as an anticyclonic event (not shown). During its further evolution, the wave (label A) comes into close proximity with the northern flank of the subtropical jet where strong cyclonic shear prevails. This shear counteracts the anticyclonic evolution and the wave is subsequently deformed cyclonically (1200 UTC 17 February 1964-1800 UTC 18 February 1964; Fig. 3b, third row) to the point where its southern tip is cut off (0000 UTC 19 February 1964). The cyclonically breaking wave is detected by the routine at 1800 UTC 18 February 1964 (Fig. 3b, second panel, third and fourth row). At the same time, a small anticyclonic wave-breaking event takes place southeastward of the cyclonic event on the subtropical jet.

The subjective visual analysis of the two cyclonic cases indicates that there are several mechanisms that can lead to a cyclonic life cycle. In the first example, presumably the jet-inherent shear asymmetry leads to the cyclonic development. In the second example, an anticyclonically breaking wave appears to be forced into a cyclonic development by the cyclonic shear zone of the second jet located southward.

\section{Climatological analyses}

\section{a. Shear and isentropic velocity composites}

The climatological winter distribution of the mean isentropic meridional shear and the wind velocities are shown in Fig. 4 on four isentropic levels (310, 320, 330, $340 \mathrm{~K})$. The meridional shear distribution exhibits some noteworthy features. On the lowest level (310 K), a 
small asymmetry of the shear distribution exists over the western Pacific. There the cyclonic shear is stronger than the anticyclonic shear. An opposite asymmetry prevails farther downstream over the central and eastern Pacific. Over the western Atlantic, the shear distribution is almost symmetrical. Further downstream the shear is in general very weak and anticyclonic except over the eastern Mediterranean (contours not shown).

At $320 \mathrm{~K}$, the shear asymmetry over the western Pacific has changed in favor of anticyclonic shear. Over the western Atlantic, the shear distribution is almost symmetrical. At higher levels $(330,340 \mathrm{~K})$, there is a general asymmetry of the shear toward the anticyclonic side that encompasses the whole hemisphere. This change in the asymmetry of the shear with height in the Pacific is partially due to the geometry of the intersection between the isentropic surfaces and the jet (see Fig. 2). The asymmetry of the jet structure, showing stronger gradients along the southern flank of the jet is apparent in both the Atlantic and the Pacific sector (Figs. 2a,b). Note that this section describes the horizontal shear on isentropic surfaces, because isentropic $\mathrm{PV}$ features are predominantly influenced by isentropic PV advection.

\section{b. Streamer frequency composites}

Figure 5 shows the winter (DJF) spatial frequency composites of cyclonic and anticyclonic PV streamers. The values indicate the percentage of time when in winter either an anticyclonic or a cyclonic PV streamer is present at a certain grid point. Substantial variations of this frequency with longitude and height exist for both streamer classes. On the lowest isentropic level $(310 \mathrm{~K})$, the intersection of the dynamical tropopause is located on the northern flank of the jet in both the Atlantic and the Pacific sectors (Figs. 2a,b). Anticyclonically (LC1) deformed PV streamers occur predominantly downstream of the Pacific and the Atlantic storm tracks. The frequency maxima are located over the southwestern United States and central Europe and Asia. The European maximum ( $>4 \%)$ is considerably stronger than the one situated over North America $(>1.5 \%)$. The LC1 streamer maximum over North America is situated at the southern edge of a weak jet, where anticyclonic shear is prevalent (contours not shown). This area downstream of the Rocky Mountains is a known upper-level trough genesis region (Sanders 1988). The LC1 frequency maximum over Europe and Asia is located downstream of the Atlantic extratropical jet branch in a region where the climatological wind speed is very small. Its location over Europe suggests a connection to two frequently observed dynamical features in the Mediterranean-PV cutoffs and (lee) cy- clones (e.g., Wernli and Schwierz 2006; Wernli and Sprenger 2007). The formation of PV cutoffs is often observed when anticyclonic streamers decay (THM) and cyclones can form beneath these cutoffs.

The two maxima in the frequency of occurrence of the cyclonically deformed PV streamers (LC2) on the $310-\mathrm{K}$ isentrope are located within the storm tracks over the Atlantic and the eastern and central Pacific. This is in good agreement with the observation that strong surface low pressure systems are a typical lowlevel feature accompanying the cyclonic life cycle (THM; Wernli et al. 1998). The maximum in the Pacific is located at the northeastern edge of the relatively strong Pacific jet. In the Atlantic, cyclonic streamers are frequently found right in the middle of the weaker Atlantic jet core.

On the 310-K level anticyclonically breaking waves are almost absent over the Pacific. One possible explanation for this observation is that the asymmetric shear in the western Pacific (cf. Fig. 4) influences the developing baroclinic waves in an early stage of their life cycle in favor of a future cyclonic development. In the Atlantic basin, such a strong asymmetry in the mean flow is not observed.

In general, the cyclonic streamer maxima are located further north than the anticyclonic ones, as is observed in idealized experiments (see section 1). Overall on the 310-K level LC2-type PV streamers are more frequent than LC1-type PV streamers. When compared to the climatological streamer frequencies in winter, about half of the climatological value, which reaches up to $9 \%$ over Europe, consists of LC1 streamers. The climatological streamer frequency maximum in the eastern $\mathrm{Pa}$ cific of about $8 \%$ can be compared to the $6 \%$ maximum of the LC2 streamers. Slightly smaller percentages of around $7 \%$ in the climatological mean and around 5\% in the LC2 sample are found in the western Atlantic (Martius 2005).

With increasing isentropic height, the streamer frequencies become smaller and spatially more confined than on the lower level (Wernli and Sprenger 2007) and the locations of the maxima of the two classes are no longer separated. Both streamer types occur in the same longitudinal sectors over the central eastern Atlantic and the central and eastern Pacific where the climatological jet velocities are decreased. The relative percentage of anticyclonic streamers increases significantly with height. Both streamer types occur on the southern edge of the jet on the higher levels (330, $340 \mathrm{~K})$.

The frequency maximum of the anticyclonic streamers in the Pacific shifts to the west with height. The absolute frequency of these streamers is highest on the 

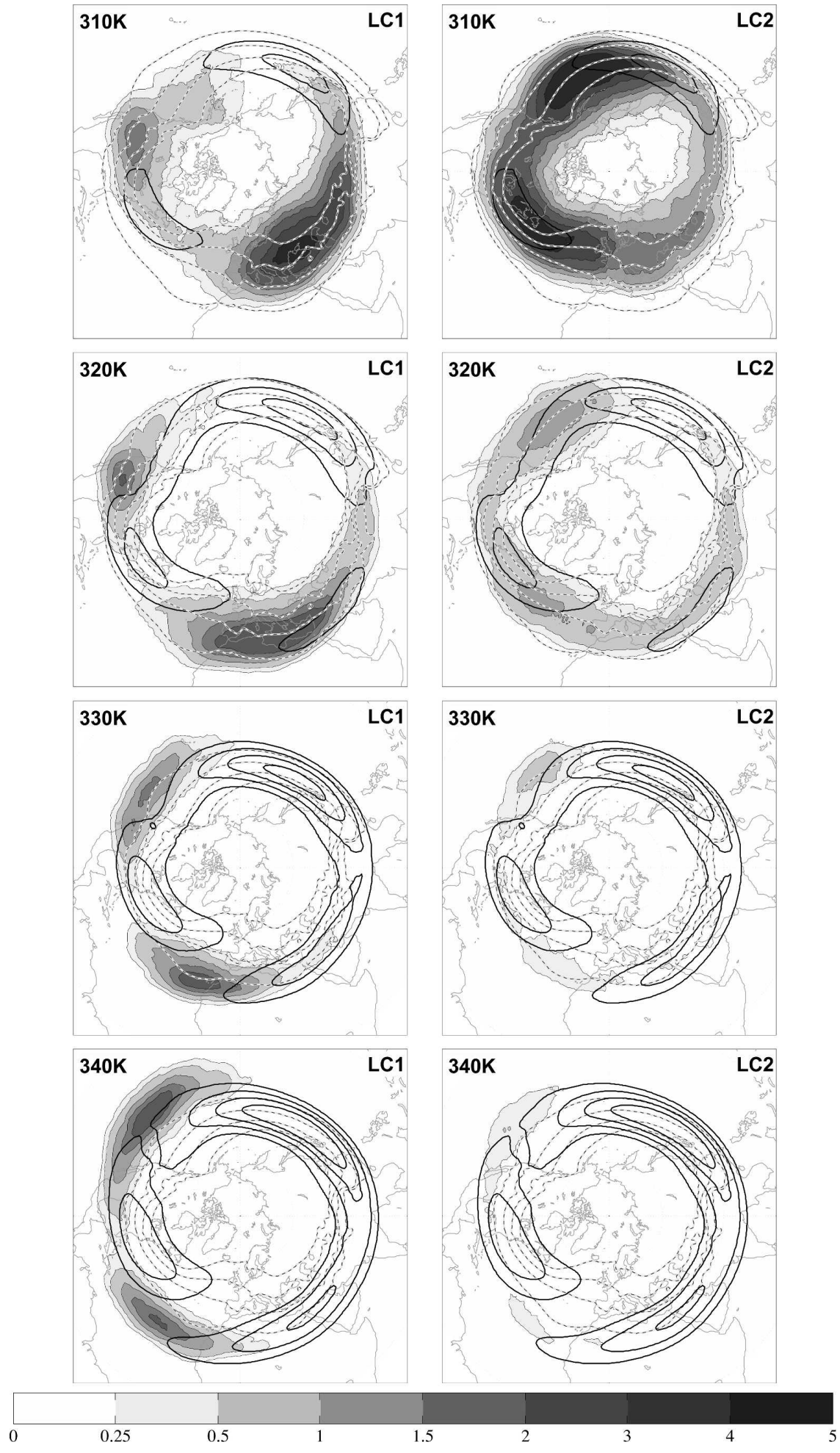

FIG. 5. Winter (DJF) climatological PV streamer frequency distribution (shaded), climatological wind speed (black lines; $30,40,50,60 \mathrm{~m} \mathrm{~s}^{-1}$ ), and mean winter isentropic temperature at $850 \mathrm{hPa}$ (dashed black and white lines; 280, 285, 290, and $295 \mathrm{~K}$ ) on four isentropic surfaces. 
340-K level. This increase is linked to a spatial extension of the streamer maximum with height and a decrease of the jet velocity to the north of the streamer maximum from 330 to $340 \mathrm{~K}$. In the Atlantic region, the highest frequency of anticyclonic streamers is found on the lowest level. With increasing height, the Atlantic anticyclonic maximum shifts toward the west. The cyclonic streamer frequency becomes insignificant above the 320-K level. Integrated over all levels, both streamer types occur approximately equally often.

Possible explanations for the changing proportion of anticyclonic and cyclonic streamers with height and decrease in latitude are as follows:

1) PV streamers in the subtropical latitudes can be indirectly influenced by tropical convection (e.g., Randel and Park 2006) and/or subtropical high-pressure systems (Postel and Hitchman 1999). In both cases, tongues of high PV are advected southward along the eastern edges of strong upper-level anticyclones, which are areas of relatively low PV. The PV streamers are in this process deformed anticyclonically by the ambient flow field.

2) The asymmetry of the isentropic horizontal shear on higher levels toward stronger anticyclonic shear (see section $4 \mathrm{a}$ and Fig. 4).

3) An equatorward displacement of a surface front relative to an upper-level jet modifies the nature of the finite-amplitude interaction between the counterpropagating waves present on the two levels such as to favor the growth of the resulting spatially more-contiguous cyclonic portions of the wave disturbances on both surfaces (Davies 1998).

4) Following the vortex-based line of argument of Orlanski (2003) the weaker low-level baroclinicity in the subtropics and strong upper-level anticyclones would lead to anticyclonic wave breaking, whereas the stronger baroclinicity of the extratropics would be favorable for cyclonic life cycles.

\section{c. Life cycles and teleconnection indices}

This section discusses changes of the frequency of occurrence of the PV streamer classes during opposite phases of large-scale atmospheric teleconnection patterns (i.e., NAO/PNA/ENSO) on the 310-K isentrope. Composites of the frequency of occurrence of different PV streamer life cycles during opposite phases of the NAO and PNA pattern are shown in Figs. 6 and 7. The frequencies can be directly compared to those of Fig. 5 in the following way. For the composites only days are used, where the NAO (PNA) indices exceed $1 \sigma$ or are below $-1 \sigma$. Hence the frequency indicates the percentage of winter days where the teleconnection indices are either significantly positive or negative and a streamer of a certain orientation class is present at one grid point. The streamer frequencies for each life cycle and extreme phase of the index are tested against a climatological Monte Carlo sample. The same amount of days as in the $> \pm 1 \sigma$ NAO (PNA) sample are randomly drawn from the climatological base sample. This procedure is repeated 200 times and the streamer frequency at each grid point is then compared to the $99 \%$ and $1 \%$ quantiles of this Monte Carlo sample for areas where the streamer frequency in the climatological sample exceeds $0.1 \%$. An analysis for the upper levels is not shown since these composites contain only a very small number of streamer cases.

For the two NAO phases, the results are presented in Fig. 6. During the positive phase of the NAO (NAO+), when the Atlantic jet extends into northwestern Europe, anticyclonic streamers are significantly more frequent over the Mediterranean area and over Eastern Europe than in the climatological mean (Fig. 6a). Note the double jet configuration in the area of the anticyclonic streamer frequency maximum. During the negative NAO phase (NAO-), with a weaker jet over the Atlantic, the LC1-streamer maximum extends northwestward into the Atlantic basin and the frequency of LC1 streamers is significantly reduced in the eastern Mediterranean (Fig. 6b). Note that even though the anticyclonic streamers are significantly more frequent across large parts of the northeastern Atlantic region, the absolute streamer frequencies are very small in this area (Fig. 6b).

The frequency of occurrence of the cyclonic life cycle in the Atlantic is also closely linked to the NAO flow pattern. LC2-type streamers become almost absent in the western Atlantic basin during NAO+ (Fig. 6c) and are significantly more frequent in the same area than in the climatological mean during NAO- (Fig. 6d). This is in good agreement with the findings of Benedict et al. (2004) and Franzke et al. (2004), who detect cyclonic wave breaking in the extratropical western Atlantic during strongly negative NAO events. An area of increased cyclonic streamer frequencies is present during $\mathrm{NAO}+$ in the eastern Pacific.

The same analysis for the PNA is shown in Fig. 7. On this level, the PV gradients are stronger over the central Pacific during the negative phase of the PNA (not shown). The differences in the streamer frequencies between the two PNA phases are significant in areas in the Pacific, where the jet is weak. In the western part of the Pacific, the differences between the two PNA phases become negligible. A significant positive signal for the LC2-type PV streamers frequency is found during the positive phase of the PNA in the eastern Pacific 

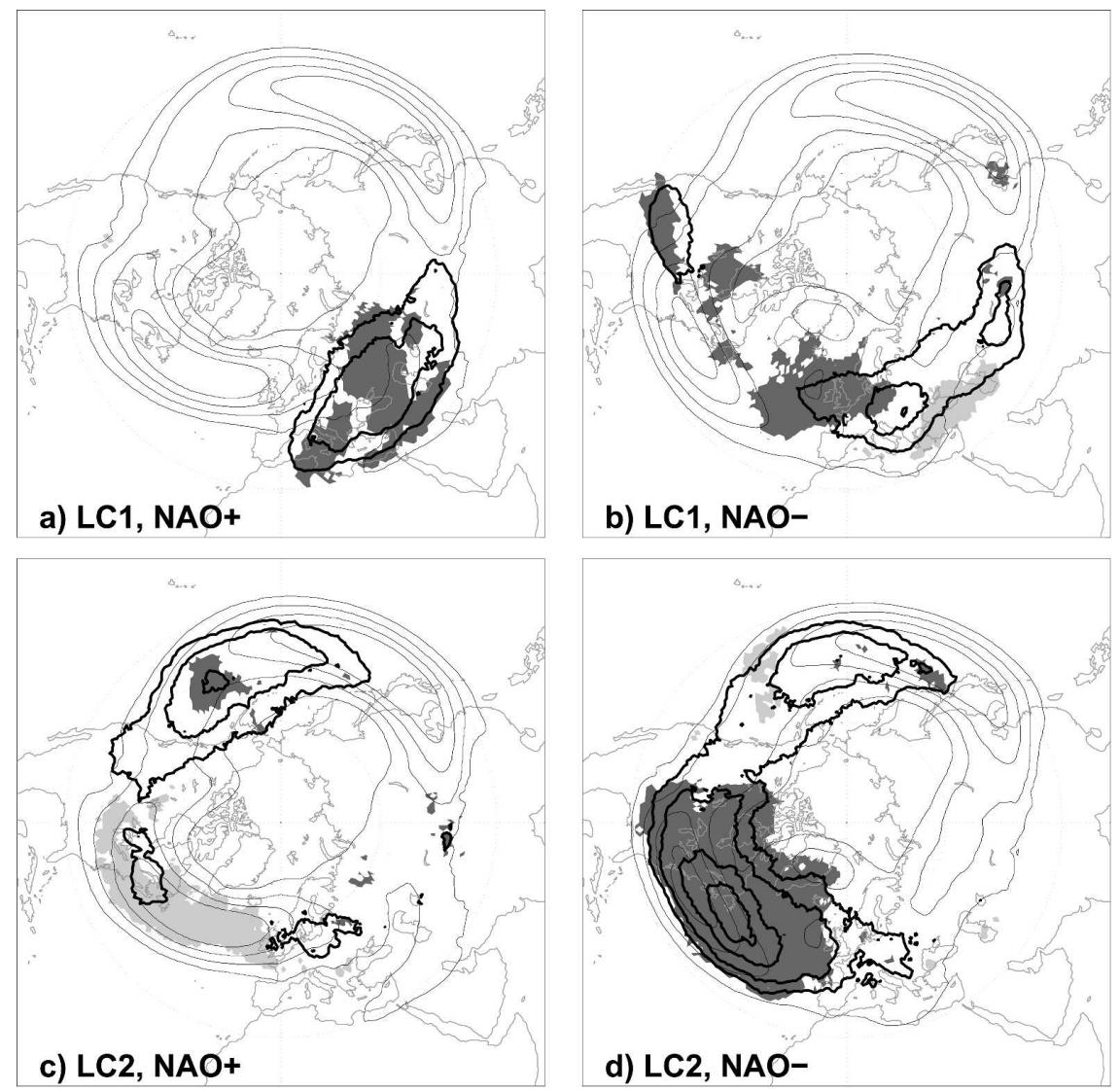

FIG. 6. Climatological PV streamer frequency distribution in percent of the time for winter (DJF) on days with NAO index exceeding one negative or positive standard deviation (heavy black lines, contour interval is the same as in Fig. 4). Areas where the PV streamer frequency is significantly different (98\%) from a climatological distribution are shaded (dark gray $>$ climatology, light gray $<$ climatology). Isentropic winds during the positive and negative phase of the NAO are overlaid (thin black lines; 20, 25, 30, $35 \mathrm{~m} \mathrm{~s}^{-1}$ ).

(Fig. 7c). During the negative PNA phase, cyclonic streamers occur significantly less often than in the climatological mean in the eastern part of the Pacific whereas more cyclonic streamers are found over northeastern America, and over the western and eastern Atlantic and northern Europe (Fig. 7d). This decrease of the streamer frequencies over the eastern Pacific is connected to a westward shift of the Pacific streamer frequency maximum and the Pacific jet core (Fig. 7). The decline of the jet velocities, which goes together with smaller PV gradients (Schwierz et al. 2004), facilitates the breaking of baroclinic waves in this area (e.g., Swanson et al. 1997). Hence, the nonlinear part of the storm track, where the majority of the baroclinic waves break, is shifted upstream.

The analyses for the ENSO phases differ from those of the NAO and the PNA insofar as monthly data are used to build the composites. As in the previous PNA example, significant differences between the two phases of the ENSO are only found in the eastern Pacific where the jets are weak.

An eastward (westward) shift of the frequency maximum of the cyclonic streamers occurs in the eastern Pacific during the warm (cold) phase of ENSO (Figs. $8 \mathrm{c}, \mathrm{d})$. This shift is closely related to the slight eastward advance of the jet maximum during the warm phase. Significantly more cyclonic streamers than in the climatology are present in the eastern Pacific during the warm phase. This is in good accordance with the findings of Shapiro et al. (2001).

\section{Flow conditions}

This section discusses the topic of single or double jet structures during cyclonic or anticyclonic wave breaking (see introduction). For this purpose, composites of the flow conditions in the tropopause region are calculated at the time and prior to the streamer detection. 

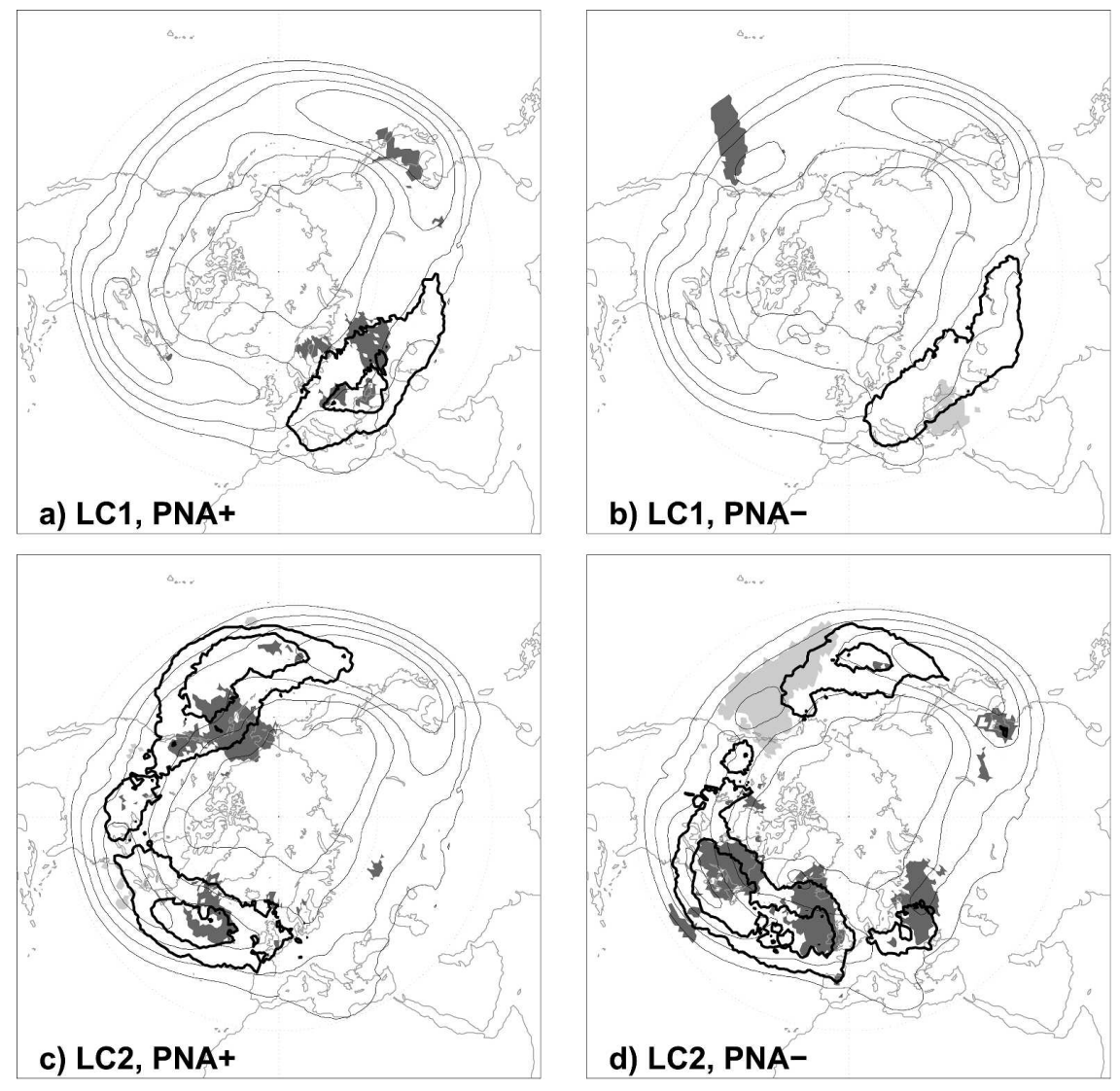

FIG. 7. The same as Fig. 6, but for PNA.

The four composites presented afterward show the two streamer life cycle classes (LC1, LC2) on the 310- and $340-\mathrm{K}$ isentropic levels. To ensure the comparability of the amplitudes of the composites, all samples are reduced to the size of the smallest group (LC2 on $340 \mathrm{~K}$ ) that comprises about 200 events. The 200 events for larger groups are randomly drawn from their base sample. These streamer samples contain cases from the entire hemisphere. Hence, specific differences between Atlantic and Pacific streamers are not resolved in the composites. For every one of the 200 events, the instantaneous PV and wind fields are calculated on isentropic surfaces and on the tropopause. These fields are then rotated so that the root point of the streamer (see Fig. 1) is located at the origin and then averaged (Fig. 9). For Fig. 10 the fields are rotated in the zonal direction only to allow a depiction of the entire Northern Hemisphere.

The breaking waves (cyclonic and anticyclonic) located at the center of the coordinate system are well captured in the rotated isentropic PV field (Fig. 9). They are clearly visible as tongues of high PV that extend southward. Thereby PV gradients are locally en- hanced within and in the surroundings of the breaking wave. The white spot in Fig. 9b is due to the intersection of the $310-\mathrm{K}$ isentropic surface with the Himalayas.

On the lower level in the case of the anticyclonically breaking wave (Fig. 9a), a wind velocity maximum is present downstream in the vicinity of the PV streamer. This is due to the asymmetric enhancement of the PV gradients during the breaking of the waves. In the case of cyclonic wave breaking (Fig. 9b), the gradients and hence the wind velocities are enhanced upstream of the breaking waves.

Remember that on the subtropical level (Fig. 9c) the mean longitudinal location of the anticyclonic streamers is approximately $45^{\circ}-90^{\circ}$ upstream of those on the 310-K level shown in Fig. 9a (see Fig. 5). On this level, maximum wind velocities $\left(>40 \mathrm{~m} \mathrm{~s}^{-1}\right)$ are found to the north and upstream of the anticyclonic streamers. This is in good agreement with the observations from our earlier example (Fig. 3a, section 3), where the strong upstream jet enhances the anticyclonic wave breaking via the advection of low PV. The downstream jet is located along the southern flank of the streamer, as was observed in the example shown in Fig. 3a. 

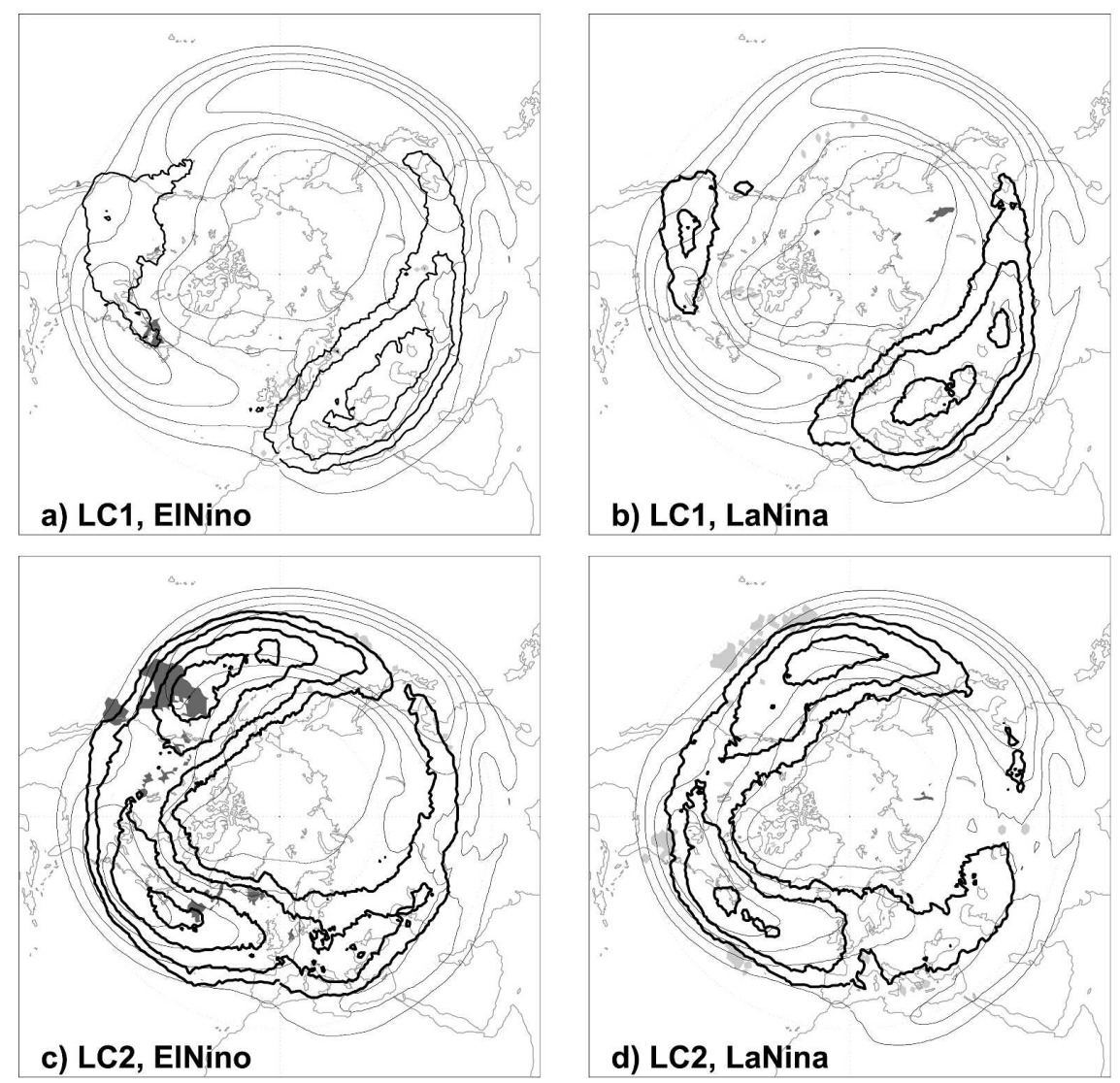

FIG. 8. Same as Fig. 6 but for ENSO.

In the cyclonic streamer composite (Fig. 9d), the maximum wind velocities $\left(>40 \mathrm{~m} \mathrm{~s}^{-1}\right)$ are located upstream and to the south of the streamer. The downstream jet on the other hand is weaker and shifted northward in the sector $0^{\circ}$ to $25^{\circ}$ pseudoeast. The events detected as cyclonic wave breaking on the higher isentropic surface are of considerable smaller spatial extent and shorter lifetime than the anticyclonic ones.

Figure 10 shows hemispheric composites of the wind velocity on the tropopause and the intersection of several isentropic surfaces with the tropopause for the same streamer samples as described above. The root points of the streamers are all located at $0^{\circ}$ pseudolongitude. The anticyclonic streamer events detected on the $310-\mathrm{K}$ level (Fig. 10a) are located about $15^{\circ} \mathrm{N}$ of a strong subtropical jet in an area of weak wind velocities and velocity gradients. Upstream of the streamer a double jet configuration is present (A) and the upstream $310-\mathrm{K}$ isentrope is located about $15^{\circ}$ farther north than in the cyclonic composite (Fig. 10b). The double jet configuration and the northward shift of the contour are also found four days prior to the wave breaking (not shown).
In the case of cyclonic wave breaking on the lower level (Fig. 10b), the breaking wave is located north of a single jet that is strong $\left(35 \mathrm{~m} \mathrm{~s}^{-1}\right)$ upstream and in the longitudinal range of the breaking wave in the sector $70^{\circ}-0^{\circ}$ pseudowest. No double jet configuration is found and the $310-\mathrm{K}$ contour is located closer to the extratropical/subtropical jet than in the anticyclonic case. This could indicate that the shear background generated by the subtropical jet can have an important influence on for the formation of cyclonically breaking waves in the extratropics (see discussion in section 3).

The anticyclonically breaking wave on the higher, subtropical level (Fig. 10c) is found on the anticyclonically sheared edge of the strong $\left(40 \mathrm{~m} \mathrm{~s}^{-1}\right)$ upstreamlocated jet $\left(120^{\circ}-0^{\circ}\right.$ pseudowest $)$. An eastward shift of this upstream jet maximum is observed prior to the wave breaking, this jet maximum is associated with an upstream large-scale wave that locally enhances the PV gradients (not shown).

The breaking wave is part of a pronounced double jet configuration. Four days earlier the flow longitudinal sector around $0^{\circ}$ pseudolongitude is characterized by a local minimum of the jet speed and a single jet configu- 

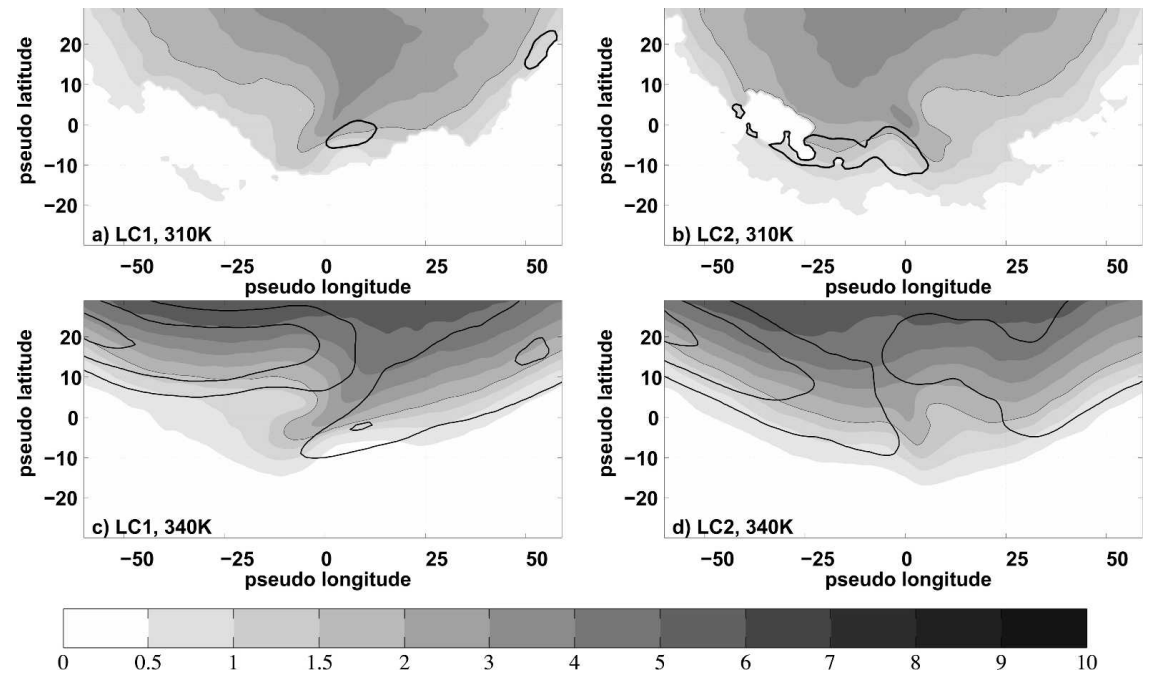

FIG. 9. Mean-PV distribution of a 200-member random sample of both streamer classes on 310 and $340 \mathrm{~K}$ rotated in such a way that the streamer root point is located at the coordinate center (shaded, 2-PVU isoline is marked by the thin black line); isentropic wind velocity (heavy black lines; 30, 40, 50, $60 \mathrm{~m} \mathrm{~s}^{-1}$ ).

ration (not shown). The speed of the downstream subtropical branch of the jet increases during the breaking process, because PV gradients and the steepness of the tropopause are enhanced in this area during the breaking process (see also Figs. 3a and 10c).

\section{Summary, conclusions, and outlook}

We have examined the climatological occurrence of cyclonically (LC2-type) and anticyclonically (LC1type) deformed stratospheric PV streamers on several isentropic surfaces $(310,320,330,340 \mathrm{~K})$ in the tropopause region. This analysis is based on a 44-yr climatology of PV streamers compiled from the ERA-40 dataset. Our working assumption is that these streamers are upper-level proxies for synoptic-scale breaking waves (e.g., Appenzeller and Davies 1992). Hence, we are able to tentatively describe the spatial distribution of cyclonically and anticyclonically breaking waves on the tropopause. A detailed and quantitative description is given of the climatological mean frequency distribution of the two types of streamers and of the deviations from this distribution during opposite phases of three major northern hemispheric teleconnection patterns. It is further possible to analyze the background flow conditions at the time of and prior to the wave breaking.

The two main results of the climatological streamer frequency analysis are 1) a change with height of the relative frequency of cyclonic and anticyclonic streamers, and 2) the clear spatial separation of the cyclonic and anticyclonic streamer frequency maxima on the 310-K level. On this level, the frequency maxima of the cyclonic streamers are situated in the area of the Pacific and the Atlantic storm track, at the downstream edges of the planetary troughs. The anticyclonically deformed streamers on the other hand occur preferentially downstream of the cyclonic maxima over Europe and less frequently over the continental United States at the eastern flanks of the planetary ridges. These results confirm observations from earlier studies that note a preference for cyclonically breaking waves in flow configurations where the jet is shifted to the south and the opposite for anticyclonically breaking waves (Hartmann 1995; Akahori and Yoden 1997). The results also agree well with the idealized findings of Orlanski (2003). The cyclonic streamers are located preferentially in areas where the surface baroclinicity is strong.

We observe a shift with increasing isentropic height from a majority of cyclonic streamers at the 310-K level to predominantly anticyclonic streamers on the 330and the 340-K level. Several mechanisms are suggested to potentially influence this change with height. First, a hemispherewide anticyclonic asymmetry of the horizontal shear across jet streams is observed on the higher isentropic levels (330, $340 \mathrm{~K}$; see Fig. 3). Second, the streamers on higher levels are located in the subtropics. Based on previous studies (e.g., Postel and Hitchman 1999), it is suggested that tropical diabatic processes potentially have a significant influence on the location and type of streamers in these latitudinal bands. Third, a southward meridional shift of the surface baroclinic 


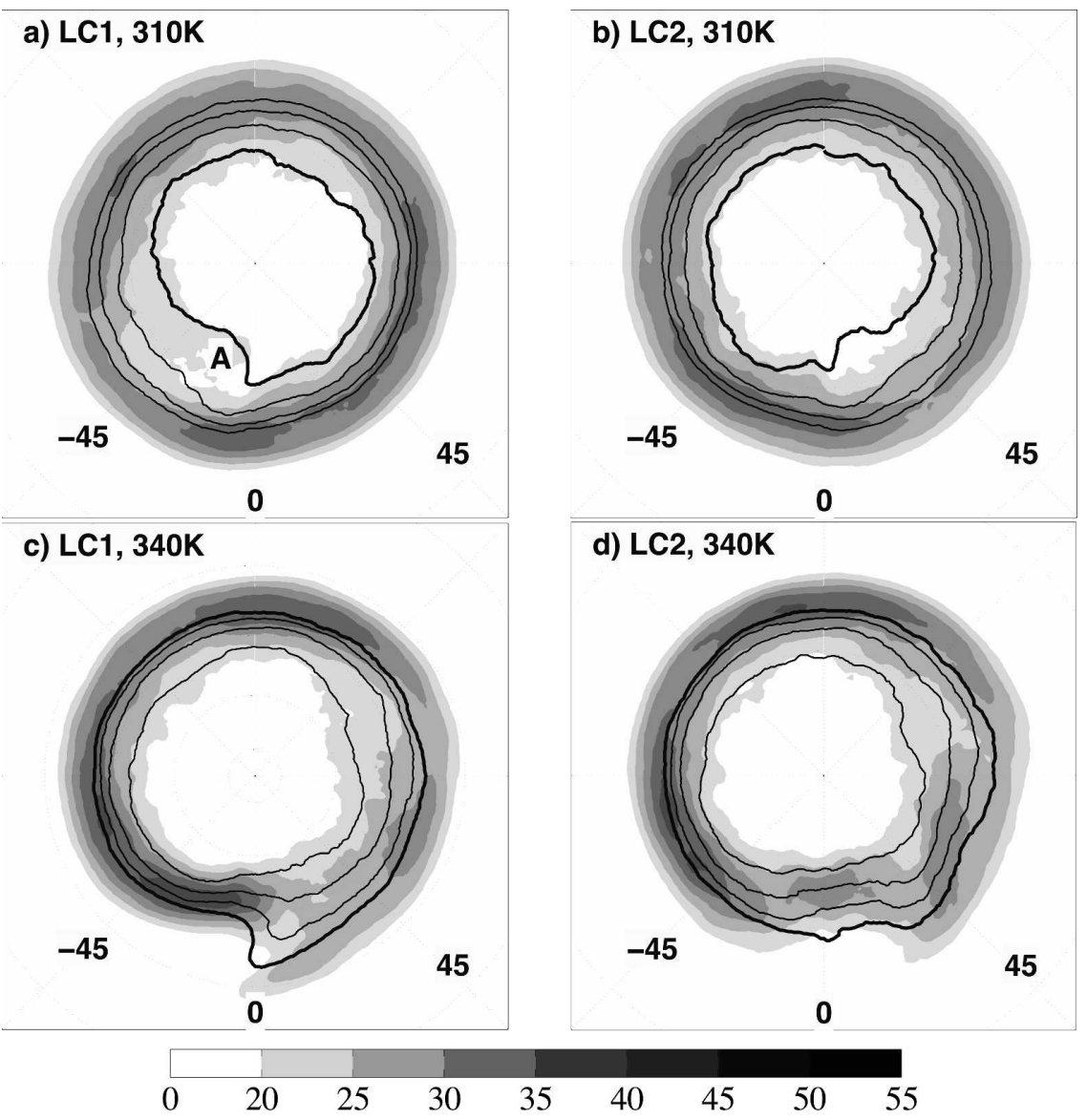

FIG. 10. Mean wind on the tropopause for the same samples as in Fig. 9 (shaded; 20, 25, 30, $35,40 \mathrm{~m} \mathrm{~s}^{-1}$ ) rotated in such a way that the streamer root point is located at $0^{\circ}$ pseudolongitude. Intersection of the tropopause with the 310-, 320-, 330-, and 340-K isentropic level (black lines, the isentrope on which the streamer is detected is bold).

zone relative to the upper-level wave can positively reinforce the cyclonic peaks of the wave (Davies 1998) and an inverse meridional shift could enhance the anticyclonic circulation of the waves. Fourth, the dominant subtropical anticyclones lead to an anticyclonic life cycle of the waves breaking in their surroundings (Orlanski 2003).

The tropospheric flow changes significantly during opposite phases of large-scale teleconnection patterns. This is on one hand expected to influence the frequency of occurrence of cyclonically and anticyclonically breaking waves (e.g., Shapiro et al. 2001). On the other hand it is suggested that the NAO pattern is significantly influenced by synoptic-scale breaking waves (Feldstein 2003; Benedict et al. 2004; Franzke et al. 2004). We find a strong link between the NAO and PV streamers on the $310-\mathrm{K}$ isentropic level. During the positive phase of the NAO, we observe increased frequencies of anticyclonic streamers over eastern and southeastern Europe compared to the climatological mean and an almost complete absence of cyclonic streamers across the entire North Atlantic basin. During the negative phase of the NAO anticyclonic streamers are more prevalent over the western part of the European continent and a significant increase of cyclonic streamers is found across the entire northern Atlantic. These results confirm the findings of Benedict et al. (2004).

For the Pacific teleconnection patterns (PNA, ENSO), we discuss only the changes in the frequency of cyclonic streamers since anticyclonic streamers are relatively infrequent over the Pacific basin on the $310-\mathrm{K}$ level. During the positive phase of the PNA and the warm phase of ENSO, an increase of the frequency of cyclonic streamers is observed in the eastern Pacific. The negative phase of the PNA is associated with a significant decrease in the cyclonic streamer frequency over the eastern Pacific and an increase of the stream- 
ers over northeastern North America, the eastern Atlantic, and northern Europe. The changes in the Pacific can be interpreted as an upstream shift of the nonlinear part of the storm track.

We have computed climatological composites of the tropospheric flow at the time of and prior to the streamer detection. These allow a detailed description of preponderance of double and single jet settings prior to and during the streamer occurrence. We observe the following flow structures in the longitudinal sectors adjacent to the streamers. Cyclonic streamers in the extratropics occur predominantly to the north of a single strong extratropical/subtropical jet. This is in line with the observations of Hartmann (1995) and the idealized findings of Esler and Haynes (1999). At the time of the detection of the anticyclonic streamers a double jet is present both on the 310 - and $340-\mathrm{K}$ isentropic level. That these climatological composites are not representative for all streamer cases becomes clear by looking at the second case presented in section 3 . There the interaction between two jets is important for the formation of a cyclonic streamer.

In summary, it can be stated that our climatological analyses confirm the transferability of the results of many idealized studies into a real-world setting. We do see, though, a clear need for further, more sophisticated idealized experiments to study feedback mechanisms between multiple jet streams and the life cycles of baroclinic waves. Another topic that deserves future attention in our opinion is the dynamical understanding of the observed PNA influence on streamers in the Atlantic and over northern Europe. A follow-up study applying the same method to tropospheric streamers and looking at other seasons is planned. It would also be interesting to extend this analysis to investigate the influence of the stratospheric flow on baroclinic life cycles (e.g., Wittman et al. 2007).

Acknowledgments. The authors thank MeteoSwiss for granting access to the ERA-40 dataset. Cordial thanks go to Heini Wernli for providing the streamer detection routine and for helpful discussions, to Mike Blackburn for many valuable comments, and to the reviewers who helped to improve the comprehensibility of this manuscript. This research is supported by the NCCR Climate program.

\section{REFERENCES}

Akahori, K., and S. Yoden, 1997: Zonal flow vacillation and bimodality of baroclinic eddy life cycles in a simple global circulation model. J. Atmos. Sci., 54, 2349-2361.

Appenzeller, C., and H. C. Davies, 1992: Structure of stratospheric intrusions into the troposphere. Nature, 358, 570-572. $\longrightarrow$ - $\longrightarrow$ and W. A. Norton, 1996: Fragmentation of stratospheric intrusions. J. Geophys. Res., 101, 1435-1456.

Balasubramanian, G., and S. T. Garner, 1997: The role of momentum fluxes in shaping the life cycle of a baroclinic wave. $J$. Atmos. Sci., 54, 510-533.

Benedict, J. J., S. Lee, and S. B. Feldstein, 2004: Synoptic view of the North Atlantic Oscillation. J. Atmos. Sci., 61, 121-144.

Bjerknes, J., 1969: Atmospheric teleconnections from the equatorial Pacific. Mon. Wea. Rev., 97, 163-172.

— polar front theory of atmospheric circulation. Geofys. Publ., 3, 1-18.

Chen, W. Y., and H. M. Van den Dool, 1997: Asymmetric impact of tropical SST anomalies on atmospheric internal variability over the North Pacific. J. Atmos. Sci., 54, 725-740.

Davies, H. C., 1998: Theories of frontogenesis. The Life Cycles of Extratropical Cyclones, M. A. Shapiro and S. Grønås, Eds., Amer. Meteor. Soc., 215-238.

, C. Schär, and H. Wernli, 1991: The palette of fronts and cyclones within a baroclinic wave development. J. Atmos. Sci., 48, 1666-1689.

De Pondeca, M. S. V., A. Barcilon, and X. Zou, 1998: The role of wave breaking, linear instability, and PV transports in model block onset. J. Atmos. Sci., 55, 2852.

Esler, J. G., and P. H. Haynes, 1999: Baroclinic wave breaking and the internal variability of the tropospheric circulation. J. Atmos. Sci., 56, 4014-4031.

Feldstein, S. B., 2003: The dynamics of NAO teleconnection pattern growth and decay. Quart. J. Roy. Meteor. Soc., 129, 901924.

Franzke, C., S. Lee, and S. B. Feldstein, 2004: Is the North Atlantic Oscillation a breaking wave? J. Atmos. Sci., 61, 145160.

Harnik, N., and E. K. M. Chang, 2004: The effects of variations in jet width on the growth of baroclinic waves: Implications for midwinter Pacific storm track variability. J. Atmos. Sci., 61, 23-40.

Hartmann, D. L., 1995: A PV view of zonal flow vacillation. $J$. Atmos. Sci., 52, 2561-2576.

— barotropic shear. J. Atmos. Sci., 55, 297-313.

Horel, J. D., and J. M. Wallace, 1981: Planetary scale atmospheric phenomena associated with the Southern Oscillation. Mon. Wea. Rev., 109, 813-829.

Hoskins, B. J., M. E. McIntyre, and A. W. Robertson, 1985: On the use and significance of isentropic potential vorticity maps. Quart. J. Roy. Meteor. Soc., 111, 877-946.

Lee, S., and H. K. Kim, 2003: The dynamical relationship between subtropical and eddy-driven jets. J. Atmos. Sci., 60, 14901503.

Martius, O., 2005: Climatological aspects of wave disturbances on the tropopause and links to extreme weather in Europe. Ph.D. thesis, Institute for Atmospheric and Climate Science, ETH Zürich, 137 pp.

— C. C. Schwierz, and H. C. Davies, 2006: Episodes of alpine heavy precipitation with an overlying elongated stratospheric intrusion: A climatology. Int. J. Climatol., 26, 1149-1164.

Massacand, A. C., H. Wernli, and H. C. Davies, 1998: Heavy precipitation on the Alpine southside: An upper-level precursor. Geophys. Res. Lett., 25, 1435-1438.

McIntyre, M. E., and T. N. Palmer, 1983: Breaking planetary waves in the stratosphere. Nature, 305, 593-600. 
Orlanski, I., 2003: Bifurcation in eddy life cycles: Implications for storm track variability. J. Atmos. Sci., 60, 993-1023.

Peters, D., and D. W. Waugh, 2003: Rossby wave breaking in the Southern Hemisphere wintertime upper troposphere. Mon. Wea. Rev., 131, 2623-2634.

Postel, G. A., and M. H. Hitchman, 1999: A climatology of Rossby wave breaking along the subtropical tropopause. J. Atmos. Sci., 56, 359-373.

Randel, W. J., and M. Park, 2006: Deep convective influence on the Asian summer monsoon anticyclone and associated tracer variability observed with AIRS. J. Geophys. Res., 111, D12314, doi:10.1029/2005JD006490.

Sanders, F., 1988: Life-history of mobile troughs in the upper westerlies. Mon. Wea. Rev., 116, 2629-2648.

Schwierz, C., S. Dirren, and H. C. Davies, 2004: Forced waves on a zonally aligned jet stream. J. Atmos. Sci., 61, 73-87.

Shapiro, M. A., and Coauthors, 1998: A planetary-scale to mesoscale perspective of the life cycles of extratropical cyclones: The bridge between theory and observations. The Life Cycles of Extratropical Cyclones, M. A. Shapiro and S. Grønås, Eds., Amer. Meteor. Soc., 139-185.

— , H. Wernli, N. A. Bond, and R. Langland, 2001: The influence of the 1997-99 El Nino Southern Oscillation on extratropical baroclinic life cycles over the eastern North Pacific. Quart. J. Roy. Meteor. Soc., 127, 331-342.

Simmons, A. J., 1998: Numerical simulations of cyclone life cycles. The Life Cycles of Extratropical Cyclones, M. A. Shapiro and S. Grønås, Eds., Amer. Meteor. Soc., 123-137.

_ , and B. J. Hoskins, 1978: The life cycles of some nonlinear baroclinic waves. J. Atmos. Sci., 35, 414-432.

— and - 1980: Barotropic influences on the growth and decay of nonlinear baroclinic waves. J. Atmos. Sci., 37, 16791684.

Sprenger, M., H. Wernli, and M. Bourqui, 2007: Stratospheretroposphere exchange and its relation to potential vorticity streamers and cutoffs near the extratropical tropopause. $J$. Atmos. Sci., 64, 1587-1602.

Swanson, K. L., 2000: Stationary wave accumulation and the generation of low-frequency variability on zonally varying flows. J. Atmos. Sci., 57, 2262-2280.

_ 2002: Dynamical aspects of extratropical tropospheric lowfrequency variability. J. Climate, 15, 2145-2162.

— , P. J. Kushner, and I. M. Held, 1997: Dynamics of barotropic storm tracks. J. Atmos. Sci., 54, 791-810.

Thorncroft, C. D., B. J. Hoskins, and M. F. McIntyre, 1993: Two paradigms of baroclinic-wave life-cycle behavior. Quart. J. Roy. Meteor. Soc., 119, 17-55.

Trenberth, K. E., G. W. Branstator, D. Karoly, A. Kumar, N. Lau, and C. Ropelewski, 1998: Progress during TOGA in understanding and modeling global teleconnections associated with tropical sea surface temperatures. J. Geophys. Res., 103, 14 291-14 324.

Uppala, M. S., and Coauthors, 2005: The ERA-40 re-analysis. Quart. J. Roy. Meteor. Soc., 131, 2961-3012.

Wernli, H., and C. Schwierz, 2006: Surface cyclones in the ERA40 dataset (1958-2001). Part I: Novel identification method and global climatology. J. Atmos. Sci., 63, 2486-2507.

- and M. Sprenger, 2007: Identification and ERA-15 climatology of potential vorticity streamers and cutoffs near the extratropical tropopause. J. Atmos. Sci., 64, 1569-1580.

—, R. Fehlmann, and D. Lüthi, 1998: The effect of barotropic shear on upper-level induced cyclogenesis: Semigeostrophic and primitive equation numerical simulations. J. Atmos. Sci., 55, 2080-2094.

Whitaker, J. S., and P. D. Sardeshmukh, 1998: A linear theory of extratropical synoptic eddy statistics. J. Atmos. Sci., 55, 237258

Wittman, M. A. H., A. J. Charlton, and L. Polvani, 2007: The effect of lower stratospheric shear on baroclinic instability. $J$. Atmos. Sci., 64, 479-496. 